\title{
Produção artesanal: documentação e divulgação audiovisual como tecnologias de valorização sociocultural
}

\author{
Luciana Alvarenga ${ }^{a}$, Samira Lima da Costa \\ aFundação Oswaldo Cruz - FIOCRUZ, Rio de Janeiro, RJ, Brasil.

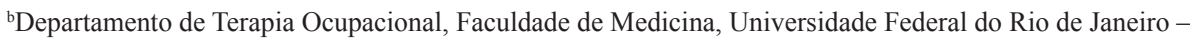 \\ UFRJ, Rio de Janeiro, RJ, Brasil.
}

\begin{abstract}
Resumo: O texto apresenta os resultados do projeto de pesquisa científica, tecnológica e de inovação na área de Economia Criativa, realizado no período de janeiro de 2014 a janeiro de 2015, cujo objetivo central foi documentar e divulgar os artesãos e a produção artesanal da Vila de Itaúnas, ES. O processo desenvolveu-se a partir de conversas iniciais, seguidas de planejamento e realização de oficinas de caráter participativo de documentação e divulgação audiovisual em torno da produção de artesanatos e de sua relação com a biodiversidade e cultura local. O objetivo inicial foi de promover espaços de expressão e de difusão do conhecimento entre e para a população local, alcançando também um público regional, estadual e nacional. Ao longo do processo, identificou-se que as oficinas participativas e a produção coletiva de um sítio virtual para divulgação das práticas e dos produtos contribuíram para a valorização e reconhecimento sociocultural do artesão e do artesanato na região.
\end{abstract}

Palavras-chave: Artesanato, Ocupação Tradicional, Valorização Cultural, Documentação, Meio Audiovisual.

\section{Handicrafts production: documentation and audiovisual dissemination as sociocultural appreciation technology}

\begin{abstract}
The paper presents the results of scientific research, technology and innovation project in the creative economy sector, conducted from January 2014 to January 2015 that aimed to document and disclose the artisans and handicraft production of Vila de Itaúnas, ES, Brasil. The process was developed from initial conversations, followed by planning and conducting participatory workshops for documentation and audiovisual dissemination around the production of handicrafts and its relation to biodiversity and local culture. The initial objective was to promote expression and diffusion spaces of knowledge among and for the local population, also reaching a regional, state and national public. Throughout the process, it was found that the participatory workshops and the collective production of a virtual site for disclosure of practices and products contributed to the development and socio-cultural recognition of artisan and craft in the region.
\end{abstract}

Keywords: Crafts, Traditional Occupation, Cultural Appreciation, Documentation, Audiovisual Dissemination.

Autor para correspondência: Samira Lima da Costa, Departamento de Terapia Ocupacional, Faculdade de Medicina, Universidade Federal do Rio de Janeiro, bloco K, sala 17, Cidade Universitária, Ilha do Fundão, CEP 21941-901, Rio de Janeiro, RJ, Brasil, e-mail: biasam2000@gmail.com Recebido em Maio 24, 2015; $1^{\text {a }}$ Revisão em Jul. 30, 2015; $2^{\text {a }}$ Revisão em Out. 30, 2015; Aceito em Nov. $30,2015$. 


\section{Introdução}

As atividades artesãs, resistindo a todo processo de produção industrializada, se mantêm entre as formas de geração de renda e de preservação da cultura popular brasileira. O material aqui apresentado é parte de um projeto de divulgaçáo cultural contemplado por edital de Ciência e Tecnologia, desenvolvido junto aos artesãos da Vila de Itaúnas, em Conceição da Barra - ES ${ }^{1}$.

A Vila de Itaúnas se localiza no extremo norte do Espírito Santo, praticamente na divisa com a Bahia. Um lugarejo bucólico de chão de terra batida, em que vivem cerca de 2.200 pessoas. Nesse lugar, encontra-se grande diversidade de manifestaçóes culturais tradicionais, em processos festivos como o ticumbi, o jongo, o alardo e o reis de boi ${ }^{2}$, além de processos produtivos artesanais como a confecção de cestos, barcos, farinheiras, entre outros. Nesse contexto, a vila se apresenta como um dos principais 'palcos' de representaçôes das tradições da região (ALVARENGA, 2011a).

Suas origens, porém, se perdem no tempo e na falta de documentos conclusivos e específicos sobre o assunto. Até meados do século XX, segundo histórias contadas pelos moradores mais antigos, a vila se resumia a duas ruas principais paralelas à praia - a de baixo e a de cima -, com castanheiras e gameleiras frondosas, cerca de 200 casas de estuque, rebocadas e assoalhadas, duas padarias, armazéns, um posto dos correios, uma escola, uma igreja na parte mais alta da vila e um cemitério. As casas eram geminadas e possuíam quintal nos fundos com árvores frutíferas, hortas, criação de galinhas e porcos. Contornando o povoado, o Rio Itaúnas era a principal via de comunicação com o mundo e, em suas margens, ficavam os barcos dos pescadores (ALVARENGA, 2011a).

Há cerca de 70 anos, porém, uma misteriosa e sutil catástrofe paulatinamente se abateu sobre o lugar. Tudo começou com uma areia fina a invadir as ruas, formando pequenos montes junto às paredes externas das casas, que era rapidamente removida com enxada ou pá sem grandes problemas, num primeiro momento. No entanto, ela passou a entrar com mais força e volume, e a se refugiar sob os móveis. Sem que isso fosse percebido, a areia que antes estava restrita à praia, passou a dominar a paisagem. Enquanto se conseguia controlar sua presença, a areia foi de certa forma tolerada. Havia dias, contudo, em que o vento ficava mais forte e a areia invadia em maior quantidade. Aos poucos, a areia modificou completamente a fisionomia da vila, e os montes tornaram-se cada vez maiores, verdadeiras dunas. A igreja e o cemitério foram os primeiros a ser soterrados. Com o passar dos anos, a vila inteira foi desaparecendo sob as enormes dunas (ALVARENGA, 2011a).

Com esse processo, a população precisou tomar medidas drásticas: alguns moradores foram embora para outras localidades, outros resolveram recriar e refundar a comunidade. A mudança da antiga vila para a nova, iniciada no final da década de 1950, quando os primeiros moradores resolveram abandonar o lugar, só veio a terminar com a saída dos últimos habitantes, em 1974. No processo do soterramento, a vila foi atravessando lentamente o Rio Itaúnas e se instalou na outra margem. Enquanto a mudança se consubstanciava de modo literal e físico, utilizava-se a imagem do que havia antes na tentativa de construir algo semelhante ou parecido. Dada a lenta invasão das dunas, foram aproveitados materiais da antiga vila na construção da nova, como madeiramento e telhas. Junto com cada parte da vila antiga que passou a compor a construção da nova vila, foram também as histórias mágicas e ricas do passado local, além de inúmeras tradições culturais. Enquanto carregavam seus móveis e pertences, os moradores levavam sua história, seus costumes e sua cultura material (ALVARENGA, 2011a). A produção cultural material dos moradores de Itaúnas se caracterizava, na vila antiga, principalmente pelos artefatos artesanais, entendendo que o artesanato seja:

Um conjunto de artefatos mais expressivos da cultura de um determinado povo e/ou regiâo, representativo de suas tradiçóes e incorporados à vida cotidiana, sendo parte integrante e indissociável dos seus usos e costumes. A produçáo, geralmente de origem familiar ou comunitária, possibilita e favorece a transferência de conhecimentos de técnicas, processos e desenhos originais. Sua importância e valor cultural decorrem do fato de preservar a memória cultural de uma comunidade, transmitida de geraçáo em geração (BRASIL, 2010, Art. 16).

A partir do deslocamento da vila, seus moradores investiram na permanência de tal produção material, fixando-a como elo de ligação com a vila antiga e com suas memórias. A presença destes antigos moradores na atual Vila de Itaúnas marca a presença da vila antiga pela produção de artesanato, como um processo de ocupaçáo tradicional.

Ocupação, entendida como direito social, é aquela que, individualmente ou coletivamente, significa e produz significado social. Dessa forma, a expressão ocupação tradicional é 
tratada como prática significante e produtora de patrimônio (material e imaterial), caracterizada pelo trabalho como mediador entre o ser humano e a natureza (COSTA, 2012, p. 44).

Compreendemos, assim, o artesanato como ocupação tradicional entre os moradores mais antigos da Vila de Itaúnas, uma vez que gera produtos elaborados com base nas interaçóes da população local com o seu meio, contribuindo para a expansão do conhecimento sobre a diversidade sociocultural e ambiental, e para a melhoria da qualidade de vida dessa comunidade, pela via do pertencimento e da identidade local.

Apesar do enorme potencial da produção de artesanatos na Vila de Itaúnas, esse ainda é pouco conhecido e valorizado. Face à complexidade e à importância dos processos que acontecem em regiôes com elevada diversidade cultural (como é o caso exemplar da Vila de Itaúnas), do volume e da qualidade das informaçóes coligidas, estudadas e sistematizadas, a divulgação deste patrimônio cultural ainda é desproporcional à sua importância e relevância. No que tange à valorização sociocultural dessa produção artesanal, essa lacuna é ainda maior.

\section{Metodologia}

O processo de mapeamento e valorização sociocultural do artesanato como ocupação tradicional na Vila de Itaúnas ocorreu ao longo do ano de 2014, tendo como disparador a observaçáo realizada previamente por uma das coordenadoras, com atividades investigativas de longa data na regiāo (ALVARENGA, 2011b). Com base nesses primeiros dados, foram levantados os nomes de alguns artesáos mais antigos, com os quais se realizaram as primeiras conversas. Em seguida, esses primeiros participantes indicaram outros e assim consecutivamente, aos moldes da rede de indicaçôes (COSTA; MENDES, 2014). A partir dessas conversas iniciais, desenvolveram-se as oficinas que geraram material escrito e audiovisual, se constituindo em objetos de análise.

Os recursos escolhidos para a valorização sociocultural dos saberes tradicionais identificados e caracterizados como artesanato foram: escuta de narrativas de memórias de vida; documentação audiovisual (KOSSOY, 2005; DARBON, 2005); e documentação e divulgaçáo da sociobiodiversidade, pautados pelos ideais dos Ecomuseus (DAVIS, 1999). Estes recursos foram marcados pela promoção de espaços efetivos de participação, de forma que o grupo envolvido no processo construísse as suas próprias narrativas e a difusão do conhecimento. $\mathrm{O}$ que se buscou nesse processo foi o desenvolvimento de um projeto de documentação e divulgação da ocupação tradicional dos artesãos de Itaúnas, aliado a um processo de inserção, sensibilização e interação deste grupo, com o estímulo à participação dos sujeitos.

A utilização de metodologia de abordagem participativa parte da perspectiva de que os participantes não se caracterizam como "objeto" e sim como sujeitos do processo (LINS, 2004; ALVARENGA; MEDEIROS, 2014; COSTA, 2012).

Para dar conta dessa diversidade de conhecimentos, o projeto de desenvolvimento e divulgação científica e tecnológica, realizado entre janeiro de 2014 e janeiro de 2015, junto aos artesãos da Vila de Itaúnas (ES), intitulado "Vida de Artesão - Documentação e Divulgação da Sociobiodiversidade e da Economia Criativa da Vila de Itaúnas, Conceição da Barra/ES" foi desenvolvido por uma equipe multidisciplinar, que atuou de maneira colaborativa e interconectada, nas áreas de memória sócio-ocupacional; ocupação tradicional; produçáo documental audiovisual; etnografia; e da identidade cultural, enfatizando a cultura material e imaterial.

Foram programadas açóes organizadas por etapas.

A) A primeira etapa consistiu no contato e na mobilização de pessoas da vila interessadas em participar do projeto. Os contatos e a mobilizaçáo foram estabelecidos através de visitas de campo às comunidades. Nessas visitas foram realizadas reunióes e debates com o intuito de apresentar e discutir a proposta do projeto, seus objetivos, sua sistemática, suas práticas e seu cronograma. Nessas reuniôes, foram acordados os processos e as práticas metodológicas que seriam desenvolvidas durante todo o projeto, ressaltando os objetivos. Nesta etapa também foi iniciada a formação de um grupo de artesãos da vila e feita a definição dos locais e das datas dos próximos encontros, gerando uma agenda em torno do cronograma executivo das oficinas.

B) Na segunda etapa do processo, foram realizadas três oficinas com o grupo definido na etapa anterior, todas com abordagem participativa, ou seja, o planejamento e a execução foram construídos coletivamente. Entre os principais instrumentos de troca de saberes, de investigação científica, de documentação e de divulgação, essas oficinas utilizaram processos interativos, como a elaboração de narrativas, a produção 
fotográfica, a produção audiovisual e a produção de um site de divulgação.

B.1) Noções de Produção audiovisual e site

Nessa oficina, inicialmente houve uma rápida apresentação sobre a produção fotográfica, de narrativas e de audiovisual, citando alguns formatos e gêneros de narrativas mais comuns para sites. No segundo momento desta mesma oficina, foram apresentados os elementos básicos da produção: das etapas aos equipamentos necessários, passando pela construção de ideias/argumentos/roteiros. Ao final dessa oficina, foi realizada uma atividade em que os participantes apresentaram os elementos narrativos que, para eles, deveriam constar na caracterização do lugar e de sua produçáo artesanal, para ser utilizado no material de divulgação: as sequências fotográficas, a produção audiovisual, o site, os cartôes de visita.

\section{B.2) Caracterização do lugar e da produção artesanal}

$\mathrm{Na}$ primeira parte desta oficina, iniciou-se a construção do quadro descritivo do lugar, localizando e identificando os artesãos, as casas, os locais de coleta da matéria-prima, entre outros elementos relevantes apresentados por eles no contexto de sua produção.

$\mathrm{Na}$ segunda parte, foram trabalhadas a memória e a história desses artesãos sobre o lugar e a produção de artesanatos. $\mathrm{Na}$ terceira, trabalhou-se com a descrição da produção de cada tipo de artesanato, incluindo desde a coleta da matéria-prima até as etapas de produção - as técnicas, práticas e saberes, inclusive as origens míticas relacionadas à cada etapa.

Durante a quarta e última parte, buscaram-se narrativas que registrassem como esses artesanatos estão inseridos no cotidiano, nas festividades e datas comemorativas, músicas, dramatizaçôes, bem como no contexto do turismo da vila.

\section{B.3) Oficina de Roteiros}

Com base nesses levantamentos, elaboramos junto aos artesãos os roteiros de conteúdo e a forma de como seria produzido o audiovisual e o website.

C) Na terceira etapa do projeto, foram realizadas a produção e a gravaçáo de documentários. Inicialmente, os roteiros foram analisados tecnicamente pela equipe do projeto, definindo e listando tudo o que teria que ser gravado, de imagens a depoimentos, e os locais de gravaçôes. Foi construído com o grupo de artesãos envolvido no projeto, um cronograma de gravação. As gravaçóes foram realizadas nos locais de produção de artesanato, nos locais de coleta da matéria-prima, entre outros.

D) A quarta etapa se desenvolveu através de três atividades: a decupagem do material gravado, o fechamento dos roteiros e a edição das imagens e textos. Na decupagem, a equipe do projeto realizou, com dois filhos dos artesáos, a transcrição escrita de todo o material gravado, entre imagens e depoimentos. Depois da decupagem, foi feito o fechamento dos roteiros e os participantes do projeto elaboraram um mapa de edição, contendo a síntese de todo o material desenvolvido e levantado até esta etapa, como sugestão de imagens, trechos de depoimentos, o texto da narração e a própria ordem e estrutura de cada página do site.

E) A quinta etapa consistiu na edição e na finalização das sequências fotográficas, das narrativas descritivas do site, do mapa temático de localização dos artesãos na Vila de Itaúnas e dos cartóes de visita por artesão.

F) A sexta etapa consistiu de apresentação do site e demais produtos do projeto ao grupo envolvido.

\section{Resultados: cultura material na Vila de Itaúnas}

$\mathrm{Na}$ atual Vila de Itaúnas, a manutenção da produção de artefatos artesanais provenientes da vila antiga está relacionada a oito artesãos: Seu Silvio Martins, Seu Paulo Jacó, Dona Jovem, Dona Iraci Martins, Seu Beto Jacó, Seu Argemiro, Seu Graciolino, Seu Benedito da Conceição ${ }^{3}$. Esses artesãos aprenderam o ofício ainda na vila antiga e nas roças localizadas no seu entorno, ou para ali vieram desde muito jovens, trazendo parte de seus saberes. $\mathrm{O}$ aprendizado foi com pais, tios e avós.

É na relação dessa comunidade com as suas histórias e com os ambientes naturais que as atividades tidas como tradicionais ainda persistem na vila nova. São os saberes e o saber-fazer considerados como aqueles provenientes dos antepassados da vila soterrada, perpetuados e reformulados no novo lugar. São conhecimentos que

[...] vieram de longe, que aprenderam com pai, que o pai aprendeu com a avó, que a avó 
aprendeu com alguém, que ninguém mais se lembra (ALVARENGA, 2011b, p. 106).

As fibras utilizadas no artesanato são encontradas na flora local. A taboa (Typha domingensis) e o junco (Eleocharis sp.) são utilizados na confecção de esteiras. $\mathrm{Na}$ mata de restinga, eles coletam o cipó para a produção de uma cestaria bastante diversificada. O arizeiro (Geoffroea spinosa) é utilizado na produção de chapéus. O bambu, juntamente com o cipó, é frequentemente utilizado na produção de apetrechos de pesca. Os samburás e jequiás possuem diversos tipos de uso, na pesca em rios, lagos e mares, e podem ser utilizados como ornamentos decorativos.

Da palha de ubá (Gynerium sagittatum) ou da folha de diversas palmeiras os artesãos produzem o tipiti, artefato utilizado para prensar a mandioca nas farinheiras e retirar o excesso de água. Com a palha também é elaborado um instrumento musical muito utilizado nas festas locais, o caxixi, que é uma espécie de chocalho: um pequeno cesto de palha trançada em forma de campânula, que pode ter vários tamanhos. Do tucum (Bactris setosa), são feitos luminárias e abajures.

$\mathrm{O}$ artesanato em madeira envolve a produção de canoas (em tamanho reduzido para o turismo), o conserto de canoas de pesca e de barcos antigos e a produçáo de carrancas e instrumentos musicais, como tambores, pandeiros e casacas (nome que se dá a um reco-reco característico do Espírito Santo).

$\mathrm{O}$ artesanato geralmente é feito na própria casa do artesão. Ele utiliza instrumentos como o buril, o formão, serrinhas, facas, goivas, canivetes, além de lixas e limas, pedaços de caco de vidro, entre outras ferramentas. Está presente no cotidiano da vila - nas atividades de pesca e coleta de sururu (com a utilização de samburás e jequiás); como utilitários e objetos decorativos (luminárias, colheres, pratos, cestos, entre outros); adornos (chapéus e bolsas); e como instrumentos musicais (tambor, casaca, pandeiro e caxixi). Estes instrumentos musicais são tradicionalmente utilizados no jongo, nos reis, no ticumbi e no alardo, ou seja, em todas as manifestações culturais presentes na Festa de São Benedito e São Sebastião. E é também na festa que se comercializa uma boa parte dos artesanatos produzidos na vila.

Assim, constatou-se que o artesanato se constitui em mensageiro de narrativas e memórias, afirmando saberes tradicionais, valorizando o passado da vila, marcando seu presente e se projetando em seu futuro, pela perspectiva da valorização sociocultural da produçáo local.
Além disso, contatou-se também a presença de processos de mudanças, de apropriação e modificação no tempo e no espaço, levando a novas significaçóes dos artesanatos locais - foi o caso dos artesanatos que sofreram processo de transformaçáo de uso, como o samburá, que é também utilizado como luminária. Verificou-se ainda a participação da produção artesanal como meio, mecanismo e efeito da permanência e fortalecimento da tradição, como os instrumentos musicais - a casaca, o pandeiro e o caxixi - que são utilizados nas manifestaçôes culturais.

A noção de tradição pressupóe permanências que podem ser auditivas (faladas, cantadas, narradas) e visuais (expressóes corporais, gestos, paisagens, etc.), referências a elementos que transportam ao passado. As tradições, porém, estão em permanente mudança, de acordo com o contexto e a situação vivida, por meio de processos de ressignificaçóes (HOBSBAWN; RANGER, 1997).

$\mathrm{Na}$ relação da vida cotidiana da Vila de Itaúnas, está presente um sistema simbólico extremamente peculiar dessa cultura organizada por um processo de continuidade entre passado e presente - os artesanatos estáo inseridos no cotidiano da vila e representam traços de uma cultura que permanece e é recriada. Este contexto é construído e reconstruído rotineiramente e constitui a história do próprio local (DE CERTEAU, 2000), uma valorização do passado em que símbolos e objetos permanecem porque contêm e perpetuam as experiências de geraçóes. A tradição na Vila de Itaúnas é um importante meio para lidar com o tempo e o espaço. $\mathrm{O}$ artesanato desse local está inserido na continuidade entre passado e presente. Estes tempos sociais são estruturados por práticas individuais, mas sobretudo coletivas e em açóes recorrentes (GIDDENS, 1991).

Neste contexto, a produção de artesanatos se constitui como elemento organizador da história desse lugar, e coloca a vila em diálogo com o mundo externo a ela. $O$ artesanato fala sobre a vila, e o artesão é o agenciador:

Se você leva o pandeiro daqui, vai levar lembrança da vila. É um presente da vila. Por que você não levando lembrança nenhuma, você náo sabe o que faz aqui (Seu Silvio).

A produção de artesanatos também é um importante meio de produçáo da vida desses artesãos, e emerge como elemento que garante aos mais velhos a possibilidade de continuidade de um fazer com sentido: 
Pra mim é um jeito de continuar vivendo, né, depois de ficar velho, continuar fazendo coisas, mostrando pras pessoas... (Seu Beto Jacó).

É importante fazer o artesanato, pra não ficar parado na vida. 'Cê faz um pouco e aí não fica parado (Seu Graciolino).

Lembrando Wilcock (2006 apud MAGALHÃES, 2013, p. 257),

[...] o fazer humano deve estar acompanhado da criação, da emoção e da aventura: em termos ocupacionais, o bem-estar através do fazer envolve acreditar que a gama potencial das ocupaçóes das pessoas permitirá a cada uma delas ser criativa, aventurar-se e encontrar sentido nas emoçóes humanas que experimentarem e explorarem no seu fazer. Significa ainda adaptar-se de forma adequada e sem interrupção indevida para atender, através do seu fazer, ao que suas vidas demandem (WILCOCK, 2006 apud MAGALHÃES, 2013, p. 257).

Além disso, a recente valorização sociocultural do saber artesão tem lhes apresentado importantes espaços de troca de conhecimentos:

A gente já deu aula lá em São Mateus, lá na Ceunes, lá no Araçá e foi bom a gente sair pra conhecer mais outros artesãos que tão lá junto com a gente. Ai a gente tava aprendendo e ensinando pra eles também (Dona Jovem).

Podemos dizer que não é o objeto que carrega o significado, mas sim o uso, é a ação simbólica que só tem sentido se comunicado neste uso,

[...] não é só com estátuas (ou pinturas, ou poemas) que temos que trabalhar, mas sim com os fatores que tornam esses objetos importantes - melhor dito, que 'afetam' de maneira importante àqueles que os fazem ou os possuem - e esses são tão variáveis como a própria vida (GEERTZ, 1997, p. 180).

[...] a variedade, que os antropólogos já aprenderam a esperar, de crenças espirituais, de sistemas de classificação, ou de estruturas de parentesco que existem entre os vários povos, e não só em suas formas mais imediatas, mas também na maneira de estar no mundo que encorajam e exemplificam, também se aplica a suas batidas de tambor, a seus entalhes, a seus cantos e danças (GEERTZ, 1997, p. 146).
Geertz (1989) apresenta o conceito de cultura como essencialmente semiótico. Entende-se que os sujeitos se constituem e se enredam às teias de significados que tecem, e à cultura como modo de expressão dessas teias. Pode-se dizer, no caso do artesanato, que "[...] a variedade da expressão é resultado da variedade de concepçóes que os seres humanos têm sobre como são e funcionam as coisas" (GEERTZ, 1989, p. 181).

É claro que qualquer coisa pode ajudar uma sociedade a funcionar, inclusive a pintura e a escultura; como também qualquer coisa pode ajudá-la a se destruir totalmente. A conexão central entre a arte e a vida coletiva, no entanto, não se encontra neste tipo de plano instrumental e sim em um plano semiótico (GEERTZ, 1997, p. 150).

A cultura é como uma rede de significados - um sistema de signos. E o signo, por sua vez, é aquilo que representa algo para alguém, em algum aspecto ou sentido (GOFFMAN, 1985). A escolha, tanto da imagética quanto da via narrativa, partiu do princípio de que sempre haverá alguém interpretando a realidade. Um signo é algo que é interpretado como um signo por um intérprete, o signo só existe quando existem seres capazes de dar significação às coisas. O signo se constitui através de dois aspectos: em primeiro lugar, o signo é algo que se vê, se ouve, se toca ou se sente; em segundo lugar, esse algo que se percebe transporta uma ideia, um conceito e um conteúdo. Está ligado ao tempo, ao espaço, ao modo de vida e às relaçôes, bem como à memória afetiva de cada um e do coletivo. A partir do momento em que se entende a percepção e a interpretação como um processo ativo, próprio ao ser humano, não se pode deixar de lado a relação existente entre estruturas cognitivas e o espaço em que estas atuam (METZ, 2004).

Neste contexto, verificou-se um processo - ora continuado, ora descontinuado - em torno da valorização sociocultural da produção artesanal dos participantes do projeto. Tal movimento se construiu ao longo da vida dos artesãos, e se entrelaça com suas experiências e memórias referentes à vida na região. Os objetos produzidos pela via artesanal ganharam valores culturais desde os primeiros momentos em que foram confeccionados na vila antiga, tendo sido referidos como produtos de necessidades básicas, em princípio, relacionados à vida cotidiana do vilarejo, justificados pela distância de outros povoados e pelo difícil acesso, somados à vida simples dos moradores do local, que produziam de forma artesanal objetos que serviam para atender à rotina da vila. Em um 
momento seguinte, com o processo de deslocamento dos moradores antigos para a nova vila (atual Vila de Itaúnas), tais objetos somam outro valor cultural: seus significados para além do sentido utilitário, mas também afetivo, passam a carregar valores materiais e imateriais da cultura local, carregando consigo e em si a vida artesá como possibilidade de permanência e continuidade das memórias.

$\mathrm{Na}$ atualidade, tais produtos têm sido identificados pelos moradores locais ao mesmo tempo como típicos da regiáo e raros - uma vez que os moradores antigos passam, com o tempo, a serem figuras escassas na Vila de Itaúnas. Ao serem convidados a participarem do projeto aqui apresentado, identificou-se um novo movimento de ressignificação com base na projeção, uma vez que os artesãos ganham visibilidade e possibilidades de colocação no mercado cultural, para o qual toda a vila parece já preparada sem, entretanto, inclui-los no processo. A visitação turística, até então mais voltada para as manifestaçôes festivas e para as atividades de cunho ecológico devido à existência de uma unidade de conservação, passa a inserir em seu mapa de visitaçôes as casas dos artesãos e seus produtos, destacando todo o processo da produção cultural material e imaterial que carregam.

\section{Considerações finais}

O projeto gerou vários processos participativos de divulgação da cultura material e imaterial da Vila de Itaúnas, tendo como eixo central os artesanatos e seus artesãos.

Dentre esses produtos, podemos citar: narrativas orais; narrativas fotográficas; produção audiovisual; mapa temático; cartôes de visita e do site Povos da Floresta e do Mar (POVOS..., 2014) que contêm a síntese de toda essa produção, exclusivo do projeto, planejado para ser o principal meio difusor dos artesãos e artesanatos da Vila de Itaúnas. O site é um importante veículo de troca de experiências, de comunicação entre a equipe e as comunidades, e de avaliação dos resultados do projeto. Nele são apresentados textos, imagens fotográficas e videográficas.

Buscamos com isso promover a potencialização da divulgação local, regional e nacional dos artesãos e dos artesanatos da Vila de Itaúnas; a ampliação da valorização sociocultural desta produção artesanal; o reconhecimento da importância da cultura local; o fortalecimento do desenvolvimento local; o aumento da interação e da troca de experiências sobre produção artesanal; o fortalecimento do turismo socioambiental e do ecoturismo na região; a ampliaçáo da conscientização da participação da populaçáo local nos processos decisórios e de gestáo socioambiental da região; a conscientização da necessidade de ampliação e fortalecimento de processos de conservação ambiental na região; a percepçáo acerca da importância da sociobiodiversidade e da produção artesanal de sua região por parte dos jovens; o aumento da compreensão da sociedade em geral sobre a importância da sociobiodivesidade e da produção artesanal; o aumento da conscientização sobre a importância da diversidade cultural e da biodiversidade, para o desenvolvimento de um país mais justo.

Identificamos, ao longo do projeto e principalmente no processo de sua análise - produzida continuamente - que a produção do material de divulgação sociocultural realizada no modelo de oficinas participativas contribuiu para que os artesãos integrantes do projeto se compreendessem enquanto atores sociais de grande relevância para a cultura local, ampliando suas possibilidades de percepção da vila e inscrevendo suas memórias não apenas nos registros da vila antiga, mas também e principalmente nos registros da vila atual. Além disso, a compreensão acerca do lugar do artesanato na região, no país e no mundo também possibilitou o redimensionamento dos sentidos de sua prática e contribuiu para o aumento quantitativo e qualitativo de suas redes de relacionamentos dentro e fora da vila.

\section{Referências}

ALVARENGA, L.; MEDEIROS, R. A imagem fotográfica e memória na representaçáo de identidades em redes sociais. In: COSTA, S.; MENDES, R. Redes sociais territoriais. São Paulo: UNIFESP, 2014. p. 115-124.

ALVARENGA, L. O Ticumbi: imagens e memória da Vila de Itaúnas. Arte \& Ensaio, Rio de Janeiro, v. 23, p. 73-79, 2011a.

ALVARENGA, L. A festa e as representaçöes culturais do ticumbi: imagens e tradiçóes da Vila de Itaúnas (ES). 2011. 225 f. Tese (Doutorado em Artes Visuais) - Universidade Federal do Rio de Janeiro, Rio de Janeiro, 2011b.

BRASIL. Secretaria de Assistência Social e Direitos Humanos do Espírito Santo. Instrução Normativa SETADES no 2 de 19/08/2010. Estabelece procedimentos, responsabilidades e competências da Setades para o desenvolvimento das atividades do Artesanato Capixaba, seguindo normas e orientaçóes do Programa do Artesanato Brasileiro (PAB). Diário Oficial [da] República Federativa do Brasil, Brasília, DF, 20 ago. 2010. Disponível em: <http://www.normasbrasil.com.br/norma/ instrucao-normativa-2-2010-es_126565.html>. Acesso em: 1 nov. 2014. 
COSTA, S. L.; MENDES, R. Redes sociais territoriais: primeiras palavras. In: COSTA, S. L.; MENDES, R. Redes sociais territoriais. São Paulo: FAP-UNIFESP, 2014. p. 17-32.

COSTA, S. L. Terapia ocupacional social: dilemas e possibilidades da atuaçáo junto a povos e comunidades tradicionais. Cadernos de Terapia Ocupacional da UFSCar, São Carlos, v. 20, n. 1, p. 43-54, 2012.

DARBON, S. O etnólogo e suas imagens. In: SAMAIN, E. O fotográfico. São Paulo: Hucitec, 2005. p. 101-111.

DAVIS, P. Ecomuseums: a sense of place. London: Leicester Museum Studies, 1999.

DE CERTEAU, M. A invenção do cotidiano: artes de fazer. Petrópolis: Vozes, 2000.

GEERTZ, C. O saber local: novos ensaios em antropologia interpretativa. Petrópolis: Vozes, 1997.

GEERTZ, C. A interpretação das culturas. Rio de Janeiro: LTC Editora, 1989.

GIDDENS, A. As consequências da modernidade. São Paulo: Editora da Universidade Estadual Paulista, 1991.
GOFFMAN, E. A representação do eu na vida cotidiana. Petrópolis: Vozes, 1985.

HOBSBAWN, E.; RANGER, T. (Org.). A invenção das tradiçôes. Rio de Janeiro: Paz e Terra, 1997.

KOSSOY, B. Fotografia e memória: reconstituição por meio da fotografia. In: SAMAIN, E. O fotográfico. São Paulo: Hucitec, 2005. p. 39-45.

LINS, C. O documentário de Eduardo Coutinho. Rio de Janeiro: Jorge Zahar Editor, 2004.

MAGALHÃES, L. Ocupação e atividade: tendências e tensóes conceituais na literatura anglófona da terapia ocupacional e da ciência ocupacional. Cadernos de Terapia Ocupacional da UFSCar, Sáo Carlos, v. 21, n. 2, p. 255-263, 2013

METZ, C. A significação do cinema. Sáo Paulo: Perspectiva, 2004

POVOS DA FLORESTA E DO MAR. CNPq: FAPERJ: FIOCRUZ, 2014. Disponível em: <http://www.povosdaflorestaedomar.com.br/>. Acesso em: 1 nov. 2014.

\section{Contribuição dos Autores}

Samira Lima da Costa participou da elaboraçáo do projeto enviado ao edital, das atividades de campo junto aos artesãos, das análises e da redação final deste artigo. Luciana Alvarenga participou da elaboração da proposta enviada ao edital, da coordenação do projeto, das atividades de campo junto aos artesãos, das análises e da redação final deste artigo. Ambas autoras aprovaram a versão final do texto.

\section{Fonte de Financiamento}

O trabalho recebeu financiamento do CNPq, através do Edital 80/2013/CNPq.

\section{Notas}

${ }^{1}$ Para tanto, foram cumpridos todos os preceitos éticos necessários à sua realizaçấo.

${ }^{2}$ Festas e expressóes culturais da região.

${ }^{3}$ Os nomes aqui apresentados são verídicos, uma vez que este é um dos principais objetivos do projeto e dos artesãos nele envolvidos: a visibilidade e a divulgação. 